Published in final edited form as:

Ann Intern Med. 2018 October 02; 169(7): ITC49-ITC64. doi:10.7326/AITC201810020.

\title{
Clostridioides difficile Infection
}

\author{
Alice Y. Guh, MD, MPH and Preeta K. Kutty, MD, MPH \\ Centers for Disease Control and Prevention, Atlanta, Georgia.
}

\begin{abstract}
Clostridioides difficile (formerly Clostridium difficile) infection is the most frequently identified health care-associated infection in the United States. $C$ difficile has also emerged as a cause of community-associated diarrhea, resulting in increased incidence of community-associated infection. Clinical illness ranges in severity from mild diarrhea to fulminant colitis and death. Appropriate management of infection requires understanding of the various diagnostic assays and therapeutic options as well as relevant measures to infection prevention. This article provides updated recommendations regarding the prevention, diagnosis, and treatment of incident and recurrent $C$ difficile infection.
\end{abstract}

\begin{abstract}
Antibiotic-associated diarrhea was described in the 1950s. By 1978, Clostridioides difficile (for-merly Clostridium difficile) had been established as the most common cause of this type of diarrhea, accounting for $15 \%$ to $25 \%$ of cases (1). The reported incidence and severity as measured by total mortality and colectomy rates increased steadily between 1993 and 2003 (2). In 2011, there were an estimated 453000 incident $C$ difficile infections in the United States, at 147.2 cases per 100000 persons, and an estimated 29300 associated deaths (3). The increased incidence, severity, and mortality of $C$ difficile infections have been largely attributed to the epidemic strain ribotype 027 (formerly referred to as NAP1/BI/027), which emerged in the early 2000s and has resulted in out-breaks in Canada, the United States, Europe, and Asia (4-6). This strain has high-level fluoroquinolone resistance, produces a binary toxin that was previously uncommon in $C$ difficile, and produces substantially (15- to 20- fold) more toxin A and B than other strains (5). It has also been linked to communityassociated disease in persons with no established risk factors, including peripartum women and children (7). Of note, from 2007 to 2010 the prevalence of ribotype 027 in England decreased significantly from $55 \%$ to $21 \%$, likely due to a concomitant reduction in fluoroquinolone use; this decrease seemed to be associated with a significant decrease in $C$ difficile incidence and mortality $(8,9)$. The emergence of another virulent strain, ribotype 078, which is found predominantly in pigs and calves, has been reported (10). This strain also causes human infection, and an association between human infection and pig farms has been observed in the Netherlands, where the prevalence of ribotype 078 has been increasing since 2005 (11). Infections caused by this strain present with similar severity as ribotype 027 but affect a younger population and are more frequently community-associated (11).
\end{abstract}

CME Objective: To review current evidence for prevention, diagnosis, treatment, and practice improvement of Clostridioides difficile infection.

Disclosures: Drs. Guh and Kutty, ACP Contributing Authors, have nothing to disclose. Forms can be viewed at www.acponline.org/ authors/icmje/ConflictOfInterestForms.do?msNum=M18-1415. 
Continued surveillance for emerging virulent strains along with judicious antibiotic use and adherence to recommended practices are critical to the prevention of $C$ difficile infection.

In 2017, the Infectious Diseases Society of America (IDSA) and the Society for Healthcare Epidemiology of America (SHEA) updated their 2010 clinical practice guidelines for $C$ difficile infection (6). Many recommendations in this article are based on these updated guidelines.

\section{Prevention}

Susceptibility to colonization with $C$ difficile occurs through alteration in the intestinal microbiota. Person-to-person transmission occurs through the fecal-oral route. Acquisition can result from direct person-to-person contact, exposure to contaminated environmental surfaces and equipment, or contact with the hands of transiently colonized health care personnel (12).

Although risk for infection is much higher in hospitalized persons than in those dwelling in the community, $C$ difficile still causes an estimated 51.9 episodes of community-associated infection per 100000 persons (7). Exposure to persons with health care-associated colonization or disease is assumed to be the most common source of community-associated infection. Limited studies suggest that the outpatient health care environment, where contamination of $C$ difficile has been found, might also be a potential source of community acquisition $(13,14)$. Studies have found that approximately $82 \%$ of persons with community-associated $C$ difficile infection had a recent outpatient health care visit $(14,15)$. Receipt of care in an emergency department in the preceding 12 weeks was found to be significantly associated with community-associated infection, independent of receiving antibiotics. This suggests that the emergency department might be a reservoir for $C$ difficile, although this exposure is only present in $11 \%$ to $24 \%$ of U.S. community-associated cases $(14,15)$. Another study found that exposure to infants aged 2 years or younger was significantly associated with community-associated infection, an exposure present in $14 \%$ of cases (16). Transmission among households and between humans, pets, and farm animals has been documented $(17,18)$. Isolation of the organism from retail meats and vegetables has also been reported (19), but none of these products have been found to be a risk factor for community-associated infection (14). Of note, $C$ difficile forms hardy spores that survive the acidic environment of the stomach. Asymptomatic colonization may occur in 3\% to $18 \%$ of patients in acute care hospitals, and increasing length of stay correlates with a greater likelihood of acquisition (20). From $4 \%$ to $20 \%$ of long-term care residents carry the organism (21). In an outbreak setting, the rate of asymptomatic colonization in a long-term care facility can be as high as $51 \%$ (22). Colonization rates in the community are estimated at $2 \%$ to $10 \%(20)$.

Once colonization is established, certain factors favor development of symptomatic disease. Antibiotic disruption of the microbial balance of the gut is the most common, and longer courses and use of multiple types of antibiotics increase the risk for disease. In addition, resistance can develop through acquisition of mobile genetic elements and other mechanisms. Exposure to certain antibiotics can select for resistant strains and drive the 
epidemic of $C$ difficile infection. For example, past outbreaks of a clindamycin-resistant strain ("J strain") were driven largely by clindamycin use (23), and the emergence of ribotype 027 has been driven primarily by fluoroquinolone use. Other antibiotics that have been associated with $C$ difficile infection include third- and fourth-generation cephalosporins and carbapenems, although almost all antibiotics carry some risk for gut microbial disruption (6). Chemotherapeutic agents may have the same effect (24). Some data suggest that proton-pump inhibitors or $\mathrm{H}_{2}$ - receptor blockers play a role in some patients, but reports are contradictory $(6,25,26)$. Further, although unnecessary use of any drug should be discouraged, there is no strong evidence that reducing use of these agents in a population prevents $C$ difficile infection. Other physical manipulations of the gastrointestinal tract, such as surgery, enemas, stool softeners, and even tubefeeding, have been identified in some studies as contributing factors (27-29). Specific immune defects, such as neutropenia or advanced HIV infection, may play a role in disease development. Finally, factors associated with general debility, such as advanced age or severe underlying disease, have been associated with increased risk, especially when multiple factors coexist $(6,30)$.

\section{What can clinicians do to reduce the likelihood of infection?}

The primary means of preventing $C$ difficile are to limit the use of antibiotics, particularly those in specific classes believed to carry particularly high risk, and to ad- here to infection prevention measures, such as the use of gloves and gowns and hand hygiene. Additional infection prevention measures include appropriate daily environmental cleaning and disinfecting.

Physicians should participate in antibiotic stewardship programs that are designed in conjunction with microbiologists, infectious disease specialists, pharmacists, infection preventionists, hospital epidemiologists, and hospital administrators. Many strategies have been used, from restricting the use of high-risk drugs to routinely reviewing antibiotic therapy and giving feedback to the treating clinicians. Stewardship protocols can also focus on improving antibiotic use for specific syndromes or conditions, such as urinary tract infections and respiratory infections.

A prospective controlled, interrupted time-series study of the geriatric service of a large teaching hospital evaluated the rates of $C$ difficile infection over 2 periods of 21 months, before and after institution of an antibiotic prescription protocol involving feedback on the appropriate use of narrow-spectrum antibiotics. After institution of the antibiotic policy, $C$ difficile infection decreased significantly (incidence rate ratio, 0.35; $\mathrm{P}=0.009)(31)$.

Because of the increasing frequency of community-associated infection, antibiotic use among outpatients may also be an important contributor to $C$ difficile infection and such use may be a target for preventing these infections.

Hospitalized patients with $C$ difficile infection should be assigned to a private room or a room with other similarly infected patients until 48 hours after diarrhea has resolved $(6,32)$. Patients with $C$ difficile infection who are colonized or infected with another multidrugresistant organism should not room with patients with $C$ difficile infection who have another multidrug-resistant organism that differs from theirs (6). Routine infection prevention 
practices include strict hand hygiene before and after every patient encounter and contact precautions that include use of disposable gloves and gowns during care of patients with $C$ difficile infection or when there is the possibility of exposure to their body fluids. Although no published trials have been designed specifically to study the protective effect of gowns, $C$ difficile has been cultured from the uniforms of hospital workers and use of disposable gowns is recommended on that basis $(6,33)$.

A prospective controlled trial examined the incidence of $C$ difficile infection on 3 similar hospital wards to evaluate the efficacy of vinyl gloves in preventing health care-associated transmission on 1 of the wards. Use of vinyl gloves was associated with a statistically significant reduction in symptomatic $C$ difficile infection and asymptomatic colonization (34).

Several studies have shown that conventional handwashing with soap and water is superior to alcohol-based hand sanitizers for removing $C$ difficile spores, and any remaining spores of $C$ difficile are highly resistant to alcohol $(35,36)$. Because organic matter interferes with alcohol's ability to inactivate all bacteria, handwashing with soap and water is recommended if there is direct contact with stool or an area with fecal contamination or when hands are visibly soiled. However, studies have failed to show a change in the rate of $C$ difficile infections when comparing alcohol-based hand products with soap and water across patient populations $(37,38)$. Moreover, even soap and water against $C$ difficile spores cannot achieve the usual 3- to 4-log reductions commonly associated with alcohol against other bacteria (39). Therefore, gloves are the primary method of preventing $C$ difficile transmission. In outbreak settings, the IDSA/SHEA guidelines recommend soap and water over alcohol-based hand products after glove removal (6).

Disposable medical equipment should be used when a patient with $C$ difficile infection is being treated. To the extent possible, medical equipment should be dedicated to the patient's room, and reusable equipment should be thoroughly cleaned and disinfected after use with a sporicidal disinfectant registered by the U.S. Environmental Protection Agency (6). Daily and terminal cleaning and disinfecting patient rooms, focusing on high-touch surfaces, should also be done (6). In an outbreak setting, interventions that included the use of a sporicidal agent for terminal disinfection have been associated with reductions in $C$ difficile infection. However, in nonoutbreak settings, terminal disinfection with a sporicidal agent has not consistently led to reductions in $C$ difficile infection. Therefore, terminal disinfection with a sporicidal agent is recommended as a supplemental intervention in outbreak settings or if there is concern of environmental transmission (e.g., repeated cases of infection in the same room) (6).

\section{Diagnosis}

\section{What history, signs, and symptoms should raise suspicion for $\boldsymbol{C}$ difficile infection?}

Patients should be asked about the known risk factors for infection (see the Box). Patients commonly develop antibiotic-related diarrhea with $C$ difficile during or shortly after receiving antibiotics, but symptoms can occur up to several months afterward. In patients 
who have been hospitalized for at least 3 days, $C$ difficile is by far the most common enteric pathogen (40).

$C$ difficile infection should be considered in patients who have diarrhea ( $\geq 3$ loose stools in 24 hours) with or without abdominal pain, especially if they have a recognized risk factor (including recent antibiotic use, hospitalization, or advanced age) with no obvious alternative diagnosis (including laxative use in the past 48 hours). Nausea, vomiting, and fever are often but not always present. Physical findings vary depending on the length and severity of disease. There may be signs of dehydration, the abdomen may be tender, and in severe cases peritoneal signs may be present. Ileus or toxic megacolon can cause abdominal distention (Table 1).

\section{What diagnostic tests should clinicians perform?}

Several diagnostic options are available, such as cell culture cytotoxicity neutralization assay (CCNA), toxigenic culture, toxin A and B enzyme immunoassays (EIAs), nucleic acid amplification tests (NAATs), and glutamate dehydrogenase (GDH) assay. However, no single test is considered to be the best laboratory testing method.

CCNA has a sensitivity of $94 \%$ to $100 \%$ and a specificity of $97 \%$; however, it takes 24 to 48 hours to obtain results and the test requires a tissue culture laboratory, which is not present in most hospitals. Toxigenic culture is more sensitive than CCNA but requires at least 48 hours for incubation, plus further testing to confirm that the isolate is a toxigenic strain. (Despite these problems, culture and molecular typing of isolates are important in epidemiologic studies.) Many commercial toxin EIAs are available to diagnose $C$ difficile infection, but they vary widely in sensitivity. Several NAATs are also commercially available and are more sensitive than toxin EIAs, but they may have lower positive predictive values depending on the pretest probability and the assay's limit of detection (6). Enzyme-linked immunosorbent as-says for GDH are very sensitive but not specific because GDH is present in both toxigenic and nontoxigenic strains.

Some authorities recommend using a multistep algorithm to diagnose $C$ difficile infection (GDH plus toxin EIA, GDH plus toxin EIA with NAAT confirmation if results are discordant, or NAAT plus toxin EIA) (6). In clinical care where testing is limited to appropriate patients (e.g., those with 3 or more unformed stools in 24 hours in the absence of laxatives) and quality measures ensure appropriate implementation, NAAT alone or a multistep algorithm is generally recommended over toxin EIA alone. If there are no prespecified criteria for $C$ difficile testing, toxin EIA as part of a multistep algorithm is recommended over NAAT alone (6) (Table 2).

Another test with diagnostic value is direct inspection via sigmoidoscopy or colonoscopy. Characteristic raised yellow mucosal plaques, or "pseudomembranes," are highly suggestive of $C$ difficile-associated diarrhea. Flexible sigmoidoscopy without colon preparation is often adequate and has been shown to be effective for establishing the diagnosis in many cases in which toxin tests yield negative results (41). However, sigmoidoscopy may miss cases that could be detected by colonoscopy because of more proximal disease (42). A limitation of direct inspection is that $C$ difficile infection often does not have pseudomembranes, which 
may be a marker of severe disease; such cases without pseudomembranes can only be detected by toxin testing or other methods.

Other tests that may provide supporting evidence for the diagnosis and are valuable in assessing disease severity and complications include complete blood count, measurement of serum creatinine and lactate levels, and computed tomography of the abdomen (Table 3).

A high leukocyte count $\left(>20 \times 10^{9}\right.$ cells/L) or elevated creatinine levels $(>176.8$ $\mu \mathrm{mol} / \mathrm{L}[>2.0 \mathrm{mg} / \mathrm{dL}]$ ) were associated with 30 -day mortality of $25.5 \%$ in a retrospective study of 1721 patients with documented $C$ difficile infection at 1 hospital over 12 years (43).

A retrospective observational cohort study of patients who required intensive care for $\mathrm{C}$ difficile infection found a lactate level of $5 \mathrm{mmol} / \mathrm{L}$ or greater to be an independent predictor of 30-day mortality (44).

Patients with $C$ difficile infection may have findings suggestive of colitis, such as mucosal thickening, on abdominal imaging (45). Complications, such as toxic megacolon or perforation, may be detected.

Repeated testing (within 7 days) during the same episode of diarrhea should be avoided. If recurrent $C$ difficile infection after successful treatment and cessation of diarrhea is suspected, testing should include toxin detection. Empirical treatment is discouraged. Testing should also not be done in asymptomatic patients. However, for research purposes or as a supplemental intervention in places with high rates of $C$ difficile infection, screening of asymptomatic patients may be reasonable (e.g., to identify asymptomatic patients potentially at risk for shedding so prevention measures can be instituted).

\section{What other diseases should be considered?}

Other infectious and noninfectious causes should be considered in patients with diarrhea and a work-up that is negative for $C$ difficile. Infectious causes include Salmonella; Shigella; Campylobacter, Shiga toxin-producing strains of Escherichia coli; and, in immunocompromised persons, cytomegalovirus, Cryptosporidia, and other opportunistic organisms. However, with the exception of cytomegalovirus and possibly other opportunistic pathogens in immunocompromised persons, these infections are unusual in patients who develop diarrhea in the hospital. Noninfectious causes include intestinal obstruction, ischemic bowel disease, inflammatory bowel disease, gastrointestinal cancer, and drugassociated diarrhea.

\section{When should clinicians refer patients to subspecialists?}

The physician should request a consultation or refer the patient if the diagnosis is uncertain. Lower endoscopy by a gastroenterologist may provide a diagnosis when results of stool studies are negative or when a diagnosis is needed more rapidly than available laboratories can provide. 


\section{Treatment}

\section{When is discontinuation of antibiotic therapy alone sufficient to treat $C$ difficile infection?}

Discontinuing antibiotic therapy should be considered in all patients with $C$ difficile infection if doing so does not jeopardize recovery from other conditions. Patients with mild diarrhea and a normal or nearly normal leukocyte count and normal creatinine levels who are otherwise not at risk for severe disease or complications may be observed for a few days to determine whether discontinuation of antibiotic therapy is sufficient to resolve the condition.

In a 10 -year prospective study of 908 patients with documented $C$ difficile diarrhea, $135(15 \%)$ responded to cessation of antibiotic use alone (46).

\section{Which supportive measures should be used?}

In addition to discontinuing use of antibiotics as soon as possible, fluid and electrolyte imbalances should be corrected. Antiperistaltic agents should be avoided because they may prevent both distribution of the therapeutic antibiotic within the gut and expulsion of the toxin.

\section{Which drugs should be used first?}

The updated IDSA/SHEA guidelines indicate that either vancomycin or fidaxomicin is recommended over metronidazole for an initial episode of $C$ difficile infection in adult patients, regardless of severity (Figure) (6). Severe disease has been variously defined, but the minimum criteria cited in the IDSA/SHEA guideline are a leukocyte count of at least 15 000 cells $/ \mathrm{mL}$ or a creatinine level greater than $1.5 \mathrm{mg} / \mathrm{dL}$ (6). The recommended dosage for nonsevere or severe disease is vancomycin, $125 \mathrm{mg}$ orally 4 times per day, or fidaxomicin, $200 \mathrm{mg} 2$ times a day for 10 days (Table 4). If either drug is unavailable or contraindicated, oral metronidazole, $500 \mathrm{mg} 3$ times per day for 10 days, may be used as an alternative for non-severe disease only. Frequent or extended use of metronidazole has been associated with potentially irreversible neurotoxicity.

In patients with fulminant disease (e.g., hypotension or shock, ileus, megacolon), vancomycin should be administered orally or by nasogastric tube at a dose of $500 \mathrm{mg} 5$ times per day. If ileus is present or other factors prevent adequate distribution through the gut lumen, instillation of vancomycin at a dose of $500 \mathrm{mg}$ in approximately $100 \mathrm{~mL}$ of normal saline per rectum every 6 hours should be considered. Intravenous metronidazole at a dose of $500 \mathrm{mg}$ every 8 hours should be added in cases of fulminant infection, especially if ileus is present (6).

Historically, metronidazole was one of the main antibiotic agents used to treat $C$ difficile infection; however, since 2000, a few randomized placebo-controlled trials have found oral vancomycin to be superior. In 1 study of 150 patients with either mild or severe disease, the overall cure rate was $97 \%$ with vancomycin versus $84 \%$ with metronidazole $(P=0.006)$; for severe disease, the cure rate was $97 \%$ with vancomycin versus $76 \%$ with metronidazole ( $P=$ $0.02)$ (47). In another trial that combined results from 2 multinational studies comparing vancomycin, metronidazole, and tolevamer (a nonantibiotic, toxinbinding polymer), clinical 
success of tolevamer (44\%) was inferior to both antibiotics $(P<0.001)$, and clinical success of metronidazole $(77 \%)$ was inferior to vancomycin $(81 \%)(P=0.02)(48)$.

Fidaxomicin has been compared with oral vancomycin in 2 randomized placebo-controlled trials. In the first study (49), the clinical cure rate with fidaxomicin was noninferior to vancomycin in both the modified intention-to-treat analysis (88\% vs. 86\%) and the per protocol analysis (92\% vs. 90\%). Significantly fewer patients treated with fidaxomicin than vancomycin had recurrent infection. In the second study (50), the clinical cure rate with fidaxomicin was also noninferior to vancomycin in both the modified intention-to-treat analysis (88\% vs. $87 \%$ ) and the per protocol analysis (92\% vs. $91 \%)$.

Teicoplanin, a glycopeptide similar to vancomycin, has been found to be equivalent or perhaps superior to vancomycin but is not available in the United States (51). Nitazoxanide, bacitracin, fusidic acid, tigecycline, rifampin, and rifaximin have also been studied, but data are limited. Limited data have shown that toxin-binding anionexchange resins, such as cholestyramine, colestipol, and tolevamer, are not consistently effective. If these agents are used, administration must be timed to minimize inactivation of concomitant vancomycin.

\section{How should patients be monitored?}

Patients should be followed for clinical evidence of expected improvement, including, where applicable, resolution of fever, reduction in stool frequency, improvement in stool consistency, normalization of abdominal examination findings, rehydration as indicated by physical examination and laboratory values, and resolution of leukocytosis. Repeated stool testing is not recommended if symptoms have resolved (i.e., no need to test for cure) because it is common for patients to remain positive for $C$ difficile after symptom resolution, and treatment of asymptomatic carriers is not indicated (6). Patients whose symptoms recur after successful treatment and resolution of diarrhea should be retested.

\section{Should probiotics be used for treatment or prevention?}

Numerous formulations of probiotics have been proposed to treat $C$ difficile colitis. The premise is that these normally non-pathogenic yeasts and bacteria may repopulate the gastrointestinal tract and limit growth of $C$ difficile; however, data are inconclusive.

A systematic review of the effects of probiotics on $C$ difficile infection found only 4 studies of acceptable size and quality. Of those, 1 showed a statistically significant reduction in the rate of relapse in patients treated with Sac-charomyces boulardii in addition to vancomycin. The authors concluded that evidence is insufficient to recommend use of probiotics, and guidelines written by an expert panel warn of $S$ boulardii fungemia in immunocompromised patients (52).

Although no recommendations exist for the use of probiotics to prevent $C$ difficile infection in patients receiving antibiotics, some meta-analyses suggest that short-term use might be safe and effective for patients who are not immunocompromised or severely debilitated (53, 54). One study indicated that hospitalized patients at high risk for $C$ difficile infection should at least be informed of the potential benefits and harms of probiotics (53). 


\section{What should be done when the patient does not respond to initial treatment?}

Patients who do not improve or who relapse after initial improvement should be reevaluated for an alternative or concurrent diagnosis or another explanation for a lack of improvement (e.g., persistent fever and leukocytosis may be due to a superimposed infection, and persistent diarrhea may be due to supplemental enteral feedings). In patients without an alternative diagnosis who do not improve, the physician must ensure that the dosage and delivery of therapy are maximized. Intravenous metronidazole and rectal instillation of vancomycin should be given if ileus might prevent orally administered vancomycin from reaching the colon. In some patients, especially those treated with metronidazole, duration of therapy may need to be extended to 14 days. In patients with fulminant infection who do not respond to vancomycin and metronidazole, tigecycline or passive immunotherapy with intravenous immunoglobulins has been used, but data are limited(6). Select patients may also benefit from surgery (see below).

\section{What are the indications for consultation?}

Consultation with a gastroenterologist or an infectious disease specialist (or both) should be considered for patients who respond slowly or relapse. Management changes may be guided by endoscopy and may include manipulation of antibiotic therapy. Surgical consultation is essential if there is evidence of perforation and should be strongly considered in patients with toxic megacolon. It may also be valuable for patients with severe illness in whom medical therapy has failed. Indicators for early surgery may include increased leukocyte count ( $\geq 25000$ cells $/ \mathrm{mL}$ ) and lactate level ( $\geq 5 \mathrm{mmol} / \mathrm{L}$ ). Both of these factors have been associated with high mortality (44).

\section{When should patients be hospitalized?}

Patients should be hospitalized for severe disease, complications, or other circumstances in which outpatient treatment is not feasible; dehydration and inability to tolerate oral medication; and signs of peritonitis, toxic megacolon, possible sepsis, or other complications. Admission should also be considered for patients who have indicators or risk factors for severe disease, such as elevated creatinine levels, leukemoid reaction, or advanced age.

\section{When should patients be admitted to intensive care?}

Admission to intensive care is necessary for patients with severe disease and an unstable clinical condition, such as septic shock, toxic megacolon, peritonitis, or severe dehydration with hypotension or end-organ dysfunction.

\section{When should surgery be considered?}

Surgery is required for patients with colonic perforation, and those with toxic megacolon, acute abdomen, or septic shock due to $C$ difficile disease (especially those with an elevated lactate level) may also benefit. Surgery may be useful in a patient without toxic megacolon in whom all medical therapies have failed. The currently recommended procedure for $C$ difficile infection is subtotal colectomy. An alternative, less-invasive procedure that 
preserves the colon is loop ileostomy with antegrade vancomycin lavage (6), but more data are needed.

\section{What should be done for patients with recurrent disease?}

Recurrent symptoms after an apparent response to initial treatment may either be relapse or infection from a different strain; regardless, diagnosis and management are the same (Figure). The updated IDSA/SHEA guidelines discuss treatment options for the first recurrent episode depending on what was used to treat the incident episode (6). The first recurrence can be treated with a 10-day course of oral vancomycin if metronidazole was used for the incident episode; a tapered, pulseddose regimen of oral vancomycin if a standard 10-day course was used for the incident episode; or a 10-day course of fidaxomicin. Data are insufficient on the utility of extending therapy beyond the recommended duration or restarting $C$ difficile infection therapy prophylactically in patients who require antibiotic treatment for another infection.

Subsequent recurrences may also be treated with oral vancomycin as a tapered, pulsed-dose regimen; a standard course of oral vancomycin followed by rifaximin; or a standard course of fidaxomicin. However, the evidence for these choices is limited.

Fecal microbiota transplantation (FMT) is recommended for patients with at least 2 prior recurrences in whom appropriate therapy has failed. Successful treatment of refractory infection by instillation of stool from healthy donors has been reported in individual cases and small case series $(55,56)$. From 2013 to 2016, at least 5 randomized controlled trials were published that compared FMT with vancomycin, autologous FMT, frozen versus fresh stool, or administration via colonoscopy versus nasogastric tube (57-61). The reported efficacy of FMT is lower in most randomized studies than in nonrandomized reports, but this may be caused by several factors, including patient selection and prior antibiotic treatment. Current data suggest that FMT is safe in the short term, and most of the associated mild to moderate adverse events are self-limited. Reported infectious complications to date have been rare, but the potential long-term infectious and noninfectious complications of FMT are unknown.

Bezlotoxumab, a human monoclonal antibody that binds to $C$ difficile toxin $\mathrm{B}$, was approved for use in the United States in 2016 to reduce risk for recurrence in high-risk persons aged 18 years or older who are receiving treatment for $C$ difficile infection (62). Bezlotoxumab is given intravenously and should be given only concurrently with antibiotic therapy for $C$ difficile infection.

\section{Practice Improvement}

\section{What do professional organizations recommend for preventing, diagnosing, and treating $C$ difficile infection?}

SHEA and IDSA have published updated clinical practice guidelines for $C$ difficile infection for both adults and children (6). The Healthcare Infection Control Practices Advisory Committee of the Centers for Disease Control and Prevention publishes periodic guidelines on infection control (63). 


\section{What other tools are available for management?}

The Centers for Disease Control and Prevention Web site has information on $C$ difficile for clinicians and patients (www.cdc.gov/hai/organisms/cdiff/cdiff_infect.html).

\section{Acknowledgment:}

The authors thank Margaret Trexler Hessen, MD, author of the previous version of this In the Clinic.

Funding Source: American College of Physicians.

\section{References}

1. Bartlett JG. Clostridium difficile: history of its role as an enteric pathogen and the current state of knowledge about the organism. Clin Infect Dis. 1994;18 Suppl 4:S265-72. [PubMed: 8086574]

2. Ricciardi R, Rothenberger DA, Madoff RD, Baxter NN. Increasing prevalence and severity of Clostridium difficile colitis in hospitalized patients in the United States. Arch Surg. 2007; 142:62431. [PubMed: 17638799]

3. Lessa FC, Mu Y, Bamberg WM, Beldavs ZG, Dumyati GK, Dunn JR, et al. Burden of Clostridium difficile infection in the United States. N Engl J Med. 2015;372:825-34. [PubMed: 25714160]

4. Loo VG, Poirier L, Miller MA, Oughton M, Libman MD, Michaud S, et al. A predominantly clonal multi-institutional outbreak of Clostridium difficile-associated diarrhea with high morbidity and mortality. N Engl J Med. 2005;353:2442-9. [PubMed: 16322602]

5. Warny M, Pepin J, Fang A, Killgore G, Thompson A, Brazier J, et al. Toxin production by an emerging strain of Clostridium difficile associated with outbreaks of severe disease in North America and Europe. Lancet. 2005;366: 1079-84. [PubMed: 16182895]

6. McDonald LC, Gerding DN, Johnson S, Bakken JS, Carroll KC, Coffin SE, et al. Clinical practice guidelines for Clostridium difficile infection in adults and children: 2017 update by the Infectious Diseases Society of America (IDSA) and Society for Healthcare Epidemiology of America (SHEA). Clin Infect Dis. 2018;66:e1-e48. [PubMed: 29462280]

7. Lessa FC, Gould CV, McDonald LC. Current status of Clostridium difficile infection epidemiology. Clin Infect Dis. 2012;55 Suppl 2:S65-70. [PubMed: 22752867]

8. Wilcox MH, Shetty N, Fawley WN, Shemko M, Coen P, Birtles A, et al. Changing epidemiology of Clostridium difficile infection following the introduction of a national ribotyping-based surveillance scheme in England. Clin Infect Dis. 2012;55: 1056-63. [PubMed: 22784871]

9. Dingle KE, Didelot X, Quan TP, Eyre DW, Stoesser N, Golubchik T, et al.; Modernising Medical Microbiology Informatics Group. Effects of control interventions on Clostridium difficile infection in England: an observational study. Lancet Infect Dis. 2017;17:411-21. [PubMed: 28130063]

10. Keel K, Brazier JS, Post KW, Weese S, Songer JG. Prevalence of PCR ribotypes among Clostridium difficile isolates from pigs, calves, and other species. J Clin Microbiol. 2007;45: 1963-4. [PubMed: 17428945]

11. Goorhuis A, Bakker D, Corver J, Debast SB, Harmanus C, Notermans DW, et al. Emergence of Clostridium difficile infection due to a new hyper-virulent strain, polymerase chain reaction ribotype 078. Clin Infect Dis. 2008;47:1162-70. [PubMed: 18808358]

12. McFarland LV, Mulligan ME, Kwok RY, Stamm WE. Nosocomial acquisition of Clostridium difficile infection. N Engl J Med. 1989;320:204-10. [PubMed: 2911306]

13. Jury LA, Sitzlar B, Kundrapu S, Cadnum JL, Summers KM, Muganda CP, et al. Outpatient healthcare settings and transmission of Clostridium difficile. PLoS One. 2013;8:e70175. [PubMed: 23894609]

14. Guh AY, Adkins SH, Li Q, Bulens SN, Farley MM, Smith Z, et al. Risk factors for communityassociated Clostridium difficile infection in adults: a case-control study. Open Forum Infect Dis. 2017;4:ofx171. [PubMed: 29732377] 
15. Chitnis AS, Holzbauer SM, Belflower RM, Winston LG, Bamberg WM, Lyons C, et al. Epidemiology of community-associated Clostridium difficile infection, 2009 through 2011. JAMA Intern Med. 2013;173: 1359-67. [PubMed: 23780507]

16. Wilcox MH, Mooney L, Bendall R, Settle CD, Fawley WN. A case-control study of communityassociated Clostridium difficile infection. J Antimicrob Che-mother. 2008;62:388-96.

17. Loo VG, Brassard P, Miller MA. Household transmission of Clostridium difficile to family members and domestic pets. Infect Control Hosp Epidemiol. 2016;37: 1342-8. [PubMed: 27767004]

18. Knetsch CW, Connor TR, Mutreja A, van Dorp SM, Sanders IM, Browne HP, et al. Whole genome sequencing reveals potential spread of Clostridium difficile between humans and farm animals in the Netherlands, 2002 to 2011. Euro Surveill. 2014;19: 20954. [PubMed: 25411691]

19. Gould LH, Limbago B. Clostridium difficile in food and domestic animals: a new foodborne pathogen? Clin Infect Dis. 2010;51:577-82. [PubMed: 20642351]

20. Donskey CJ, Kundrapu S, Deshpande A. Colonization versus carriage of Clostridium difficile. Infect Dis Clin North Am. 2015;29:13-28. [PubMed: 25595843]

21. Simor AE, Bradley SF, Strausbaugh LJ, Crossley K, Nicolle LE; SHEA Long-Term-Care Committee. Clostridium difficile in long-term-care facilities for the elderly. Infect Control Hosp Epidemiol. 2002;23:696-703. [PubMed: 12452300]

22. Riggs MM, Sethi AK, Zabarsky TF, Eckstein EC, Jump RL, Donskey CJ. Asymptomatic carriers are a potential source for transmission of epidemic and nonepidemic Clostridium difficile strains among long-term care facility residents. Clin Infect Dis. 2007;45: 992-8. [PubMed: 17879913]

23. Johnson S, Samore MH, Farrow KA, Killgore GE, Tenover FC, Lyras D, et al. Epidemics of diarrhea caused by a clindamycin-resistant strain of Clostridium difficile in four hospitals. N Engl J Med. 1999;341:1645-51. [PubMed: 10572152]

24. Anand A, Glatt AE. Clostridium difficile infection associated with antineoplastic chemotherapy: a review. Clin Infect Dis. 1993;17:109-13. [PubMed: 8353229]

25. Shah S, Lewis A, Leopold D, Dunstan F, Woodhouse K. Gastric acid suppression does not promote clostridial diarrhoea in the elderly. QJM. 2000;93:175-81. [PubMed: 10751237]

26. Dial S, Delaney JA, Barkun AN, Suissa S. Use of gastric acid-suppressive agents and the risk of community-acquired Clostridium difficile-associated disease. JAMA. 2005;294: 2989-95. [PubMed: 16414946]

27. McFarland LV, Surawicz CM, Stamm WE. Risk factors for Clostridium difficile carriage and $C$. difficile-associated diarrhea in a cohort of hospitalized patients. J Infect Dis. 1990;162:678-84. [PubMed: 2387993]

28. Thibault A, Miller MA, Gaese C. Risk factors for the development of Clostridium difficileassociated diarrhea during a hospital outbreak. Infect Control Hosp Epidemiol. 1991;12:345-8. [PubMed: 2071877]

29. Bliss DZ, Johnson S, Savik K, Clabots CR, Willard K, Gerding DN. Acquisition of Clostridium difficile and Clostridium difficile-associated diarrhea in hospitalized patients receiving tube feeding. Ann Intern Med. 1998;129:1012-9. [PubMed: 9867755]

30. Kyne L, Sougioultzis S, McFarland LV, Kelly CP. Underlying disease severity as a major risk factor for nosocomial Clostridium difficile diarrhea. Infect Control Hosp Epidemiol. 2002;23: 653-9. [PubMed: 12452292]

31. Fowler S, Webber A, Cooper BS, Phimister A, Price K, Carter Y, et al. Successful use of feedback to improve antibiotic prescribing and reduce Clostridium difficile infection: a controlled interrupted time series. J Antimicrob Chemother. 2007;59: 990-5. [PubMed: 17387117]

32. Banach DB, Bearman G, Barnden M, Hanrahan JA, Leekha S, Morgan DJ, et al. Duration of contact precautions for acute-care settings. Infect Control Hosp Epidemiol. 2018;39:127-44. [PubMed: 29321078]

33. Perry C, Marshall R, Jones E. Bacterial contamination of uniforms. J Hosp Infect. 2001;48: 23841. [PubMed: 11439013]

34. Johnson S, Gerding DN, Olson MM, Weiler MD, Hughes RA, Clabots CR, et al. Prospective, controlled study of vinyl glove use to interrupt Clostridium difficile nosocomial transmission. Am J Med. 1990;88:137-40. [PubMed: 2301439] 
35. Oughton MT, Loo VG, Dendukuri N, Fenn S, Libman MD. Hand hygiene with soap and water is superior to alcohol rub and antiseptic wipes for removal of Clostridium difficile. Infect Control Hosp Epidemiol. 2009;30:939-44. [PubMed: 19715426]

36. Jabbar U, Leischner J, Kasper D, Gerber R, Sambol SP, Parada JP, et al. Effectiveness of alcoholbased hand rubs for removal of Clostridium difficile spores from hands. Infect Control Hosp Epidemiol. 2010; 31:565-70. [PubMed: 20429659]

37. Gordin FM, Schultz ME, Huber RA, Gill JA. Reduction in nosocomial transmission of drugresistant bacteria after introduction of an alcohol-based handrub. Infect Control Hosp Epidemiol. 2005; 26:650-3. [PubMed: 16092747]

38. Rupp ME, Fitzgerald T, Puumala S, Anderson JR, Craig R, Iwen PC, et al. Prospective, controlled, cross-over trial of alcohol-based hand gel in critical care units. Infect Control Hosp Epidemiol. 2008; 29:8-15. [PubMed: 18171181]

39. Edmonds SL, Zapka C, Kasper D, Gerber R, McCormack R, Macinga D, et al. Effectiveness of hand hygiene for removal of Clostridium difficile spores from hands. Infect Control Hosp Epidemiol. 2013; 34:302-5. [PubMed: 23388366]

40. National Clostridium difficile Standards Group. National Clostridium Difficile Standards Group: report to the Department of Health. J Hosp Infect. 2004;56 Suppl 1:1-38.

41. Johal SS, Hammond J, Solomon K, James PD, Mahida YR. Clostridium difficile associated diarrhoea in hospitalised patients: onset in the community and hospital and role of flexible sigmoidoscopy. Gut. 2004; 53:673-7. [PubMed: 15082585]

42. Tedesco FJ, Corless JK, Brownstein RE. Rectal sparing in antibiotic-associated pseudomembranous colitis: a prospective study. Gastroenterology. 1982; 83:1259-60. [PubMed: 7129030]

43. Pépin J, Valiquette L, Alary ME, Villemure P, Pelletier A, Forget K, et al. Clostridium difficileassociated diarrhea in a region of Quebec from 1991 to 2003: a changing pattern of disease severity. CMAJ. 2004; 171:466-72. [PubMed: 15337727]

44. Lamontagne F, Labbé AC, Haeck O, Lesur O, Lalancette M, Patino C, et al. Impact of emergency colectomy on survival of patients with fulminant Clostridium difficile colitis during an epidemic caused by a hypervirulent strain. Ann Surg. 2007;245:267-72. [PubMed: 17245181]

45. Ash L, Baker ME, O’Malley CM Jr, Gordon SM, Delaney CP, Obuchowski NA. Colonic abnormalities on CT in adult hospitalized patients with Clostridium difficile colitis: prevalence and significance of findings. AJR Am J Roentgenol. 2006;186: 1393-400. [PubMed: 16632736]

46. Olson MM, Shanholtzer CJ, Lee JT Jr, Gerding DN. Ten years of prospective Clostridium difficileassociated disease surveillance and treatment at the Minneapolis VA Medical Center, 1982-1991. Infect Control Hosp Epidemiol. 1994; 15:371-81. [PubMed: 7632199]

47. Zar FA, Bakkanagari SR, Moorthi KM, Davis MB. A comparison of vancomycin and metronidazole for the treatment of Clostridium difficile- associated diarrhea, stratified by disease severity. Clin Infect Dis. 2007;45:302-7. [PubMed: 17599306]

48. Johnson S, Louie TJ, Gerding DN, Cornely OA, Chasan-Taber S, Fitts D, et al.; Polymer Alternative for CDI Treatment (PACT) investigators. Vancomy-cin, metronidazole, or tolevamer for Clostridium difficile infection: results from two multinational, randomized, controlled trials. Clin Infect Dis. 2014;59:345-54. [PubMed: 24799326]

49. Louie TJ, Miller MA, Mullane KM, Weiss K, Lentnek A, Golan Y, et al.; OPT-80-003 Clinical Study Group. Fidaxomicin versus vancomycin for Clostridium difficile infection. N Engl J Med. 2011;364:422-31. [PubMed: 21288078]

50. Cornely OA, Crook DW, Esposito R, Poirier A, Somero MS, Weiss K, et al.; OPT-80-004 Clinical Study Group. Fidaxomicin versus vancomycin for infection with Clostridium difficile in Europe, Canada, and the USA: a double-blind, non-inferiority, randomised controlled trial. Lancet Infect Dis. 2012; 12:281-9. [PubMed: 22321770]

51. Nelson R Antibiotic treatment for Clostridium difficile-associated diarrhea in adults. Cochrane Database Syst Rev. 2007: CD004610. [PubMed: 17636768]

52. Pillai A, Nelson R. Probiotics for treatment of Clostridium difficile- associated colitis in adults. Cochrane Database Syst Rev. 2008: CD004611. [PubMed: 18254055] 
53. Goldenberg JZ, Ma SS, Saxton JD, Martzen MR, Vandvik PO, Thorlund K, et al. Probiotics for the prevention of Clostridium difficile-associated diarrhea in adults and children. Cochrane Database Syst Rev. 2013: CD006095. [PubMed: 23728658]

54. Pattani R, Palda VA, Hwang SW, Shah PS. Probiotics for the prevention of antibiotic-associated diarrhea and Clostridium difficile infection among hospitalized patients: systematic review and meta-analysis. Open Med. 2013;7:e56-67. [PubMed: 24348885]

55. Gustafsson A, LundTønnesen S, Berstad A, Midtvedt T, Norin E. Faecal short-chain fatty acids in patients with antibiotic-associated diarrhoea, before and after faecal enema treatment. Scand J Gastroenterol. 1998;33:721-7. [PubMed: 9712236]

56. Aas J, Gessert CE, Bakken JS. Recurrent Clostridium difficile colitis: case series involving 18 patients treated with donor stool administered via a nasogastric tube. Clin Infect Dis. 2003;36: 580-5. [PubMed: 12594638]

57. van Nood E, Vrieze A, Nieuwdorp M, Fuentes S, Zoetendal EG, de Vos WM, et al. Duodenal infusion of donor feces for recurrent Clostridium difficile. N Engl J Med. 2013;368:407-15. [PubMed: 23323867]

58. Cammarota G, Masucci L, Ianiro G, Bibbò S, Dinoi G, Costamagna G, et al. Randomised clinical trial: faecal microbiota trans-plantation by colonoscopy vs. vancomycin for the treatment of recurrent Clostridium difficile infection. Aliment Pharmacol Ther. 2015;41: 835-43. [PubMed: 25728808]

59. Youngster I, Sauk J, Pindar C, Wilson RG, Kaplan JL, Smith MB, et al. Fecal microbiota transplant for relapsing Clostridium difficile infection using a frozen inoculum from unrelated donors: a randomized, open-label, controlled pilot study. Clin Infect Dis. 2014;58:1515-22. [PubMed: 24762631]

60. Lee CH, Steiner T, Petrof EO, Smieja M, Roscoe D, Nematallah A, et al. Frozen vs fresh fecal microbiota transplantation and clinical resolution of diarrhea in patients with recurrent Clostridium difficile infection: a randomized clinical trial. JAMA. 2016; 315:142-9. [PubMed: 26757463]

61. Kelly CR, Khoruts A, Staley C, Sadowsky MJ, Abd M, Alani M, et al. Effect of fecal microbiota transplantation on recurrence in multiply recurrent Clostridium difficile infection: a randomized trial. Ann Intern Med. 2016;165:609-16. [PubMed: 27547925]

62. Wilcox MH, Gerding DN, Poxton IR, Kelly C, Nathan R, Birch T, et al.; MODIFY I and MODIFY II Investigators. Bezlotoxumab for prevention of recurrent Clostridium difficile infection. N Engl J Med. 2017;376:305-17. [PubMed: 28121498]

63. Siegel JD, Rhinehart E, Jackson M, Chiarello L; the Healthcare Infection Control Practices Advisory Committee. 2007 Guideline for Isolation Precautions: Preventing Transmission of Infectious Agents in Healthcare Settings. Accessed at www.cdc.gov/hicpac/2007ip/2007isolationprecautions.html on 18 August 2010. 


\section{CLINICAL BOTTOM LINE}

Prevention... Health care-associated transmission of $C$ difficile can be prevented by careful adherence to contact precautions when infected persons are being cared for, thorough hand hygiene before and after patient encounters as well as in cases of contact with body fluids or secretions or with objects in the environment of a patient with $C$ difficile infection, and daily and terminal cleaning of patient rooms. Judicious use of antibiotics through stewardship protocols may prevent symptomatic disease in colonized patients. 


\section{Risk Factors for Clostridioides difficile Infection}

- $\quad$ Antibiotic use: Clindamycin, cephalosporins, carbapenems, and fluoroquinolones have been implicated most frequently, but all antibiotics have been associated. Risk increases with duration of use and number of antibiotics

- $\quad$ Antineoplastic agents

- Hospital or nursing home care, although community-associated disease without previous hospital or nursing home exposure is becoming more common

- $\quad$ Advanced age

- Underlying disease: Cancer, renal failure, generalized debility

- Gastrointestinal manipulation: Surgery, tube-feeding, and enemas; use of proton-pump inhibitors or $\mathrm{H}_{2}$-receptor blockers may also be associated 


\section{CLINICAL BOTTOM LINE}

Diagnosis... Several tests are available to detect $C$ difficile in stool; endoscopy can also be useful. Other laboratory tests and imaging studies are helpful in supporting the diagnosis and in determining the presence of complications or indicators of poor outcome that require hospitalization and aggressive treatment. 


\section{CLINICAL BOTTOM LINE}

Treatment... Either vancomycin or fidaxomicin should be used for mild or severe disease in adult patients. Patients with ileus or very severe disease may benefit from rectal instillation of vancomycin and intravenous metronidazole in addition to oral vancomycin. Multiple recurrences may require treatment with vancomycin as a tapered, pulsed-dose regimen; fidaxomicin; or FMT. Bezlotoxumab may be used to prevent recurrent $C$ difficile infection in adult patients at increased risk for recurrence. 
Discontinue or modify antibiotics if possible; most patients also require specific treatment

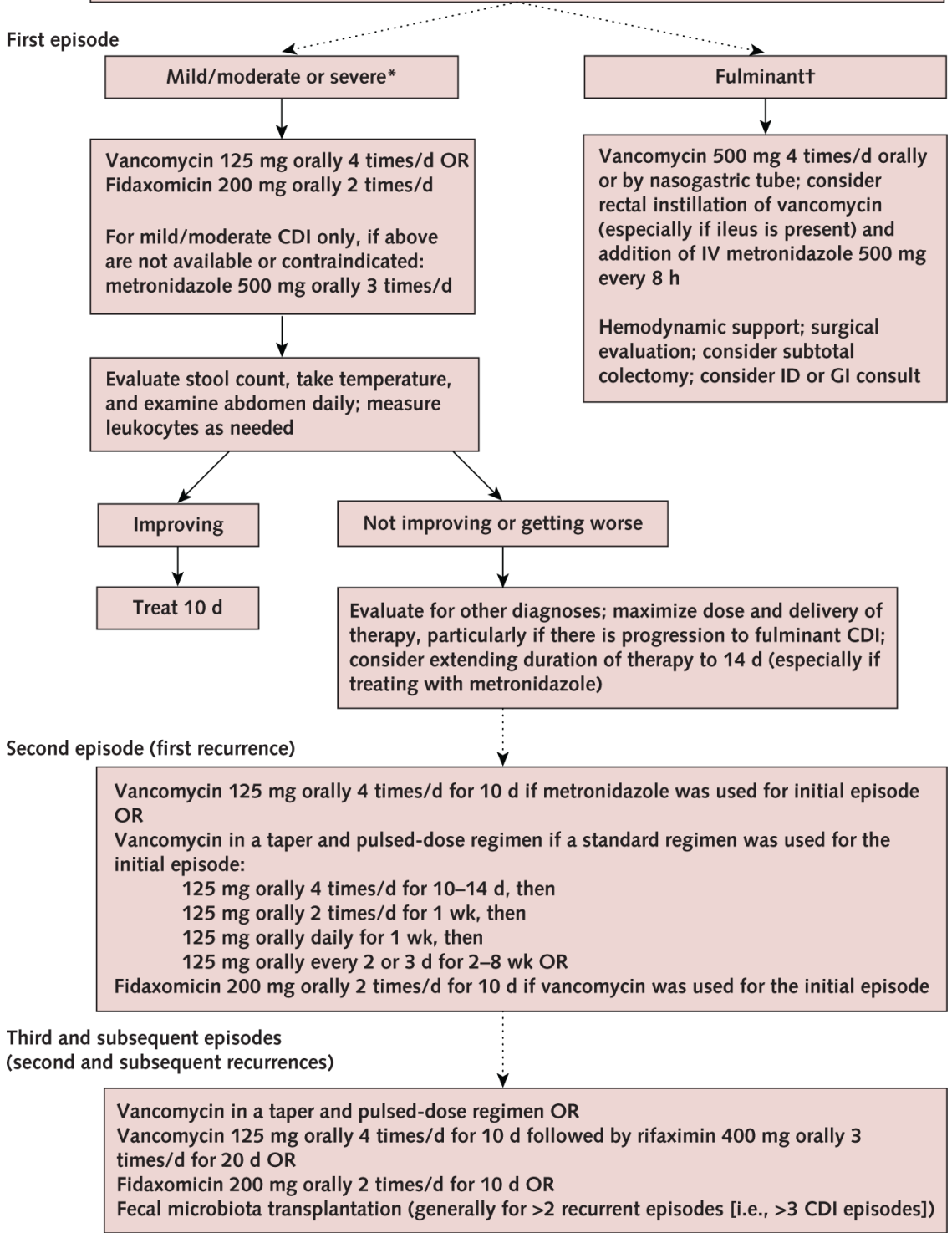

Figure.

Treatment strategies for Clostridioides difficile infection. 


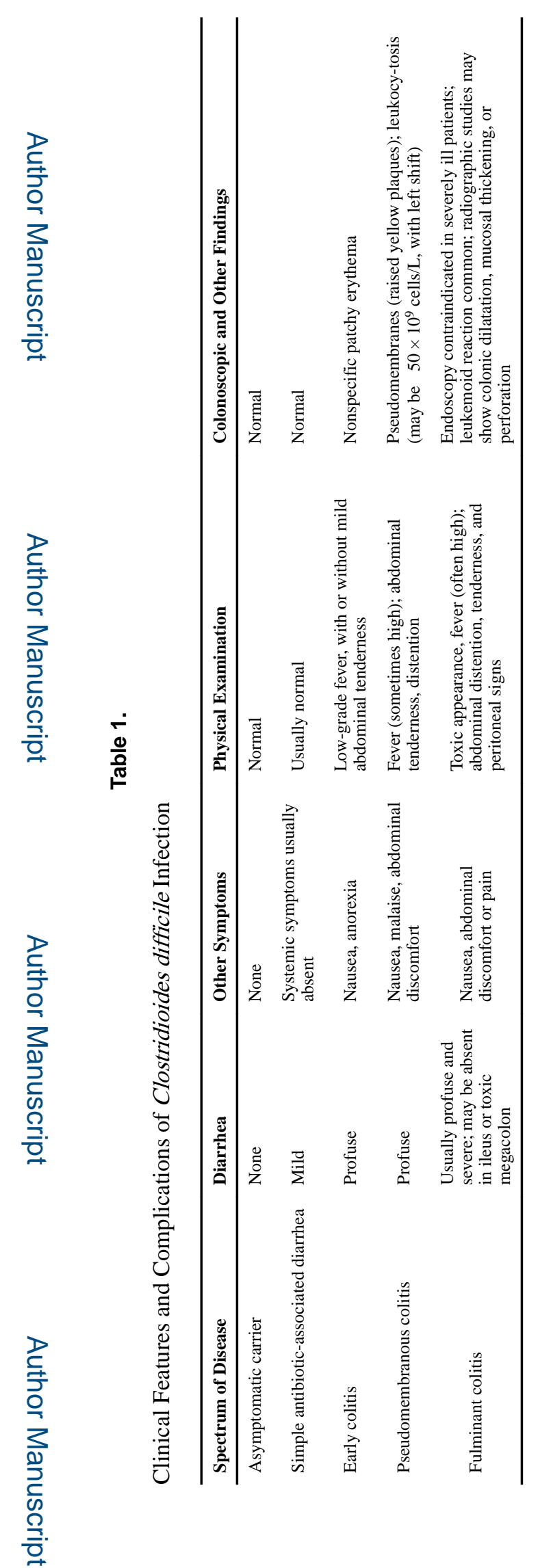

Ann Intern Med. Author manuscript; available in PMC 2019 October 02. 


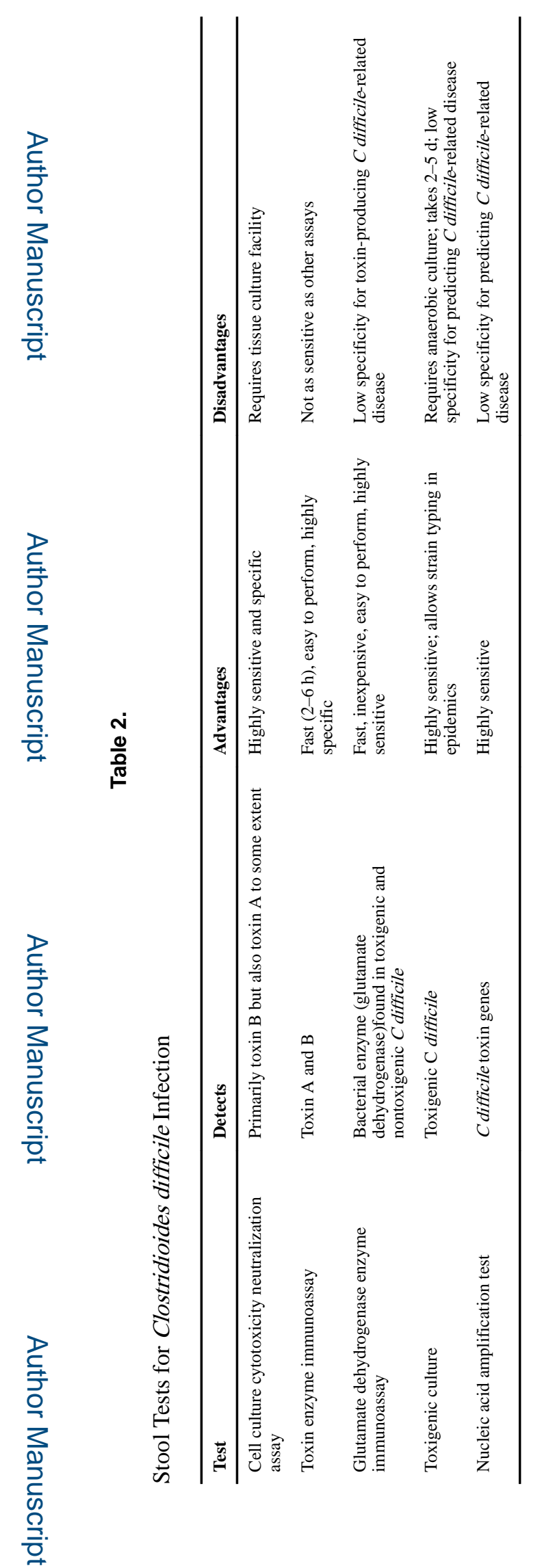

Ann Intern Med. Author manuscript; available in PMC 2019 October 02. 


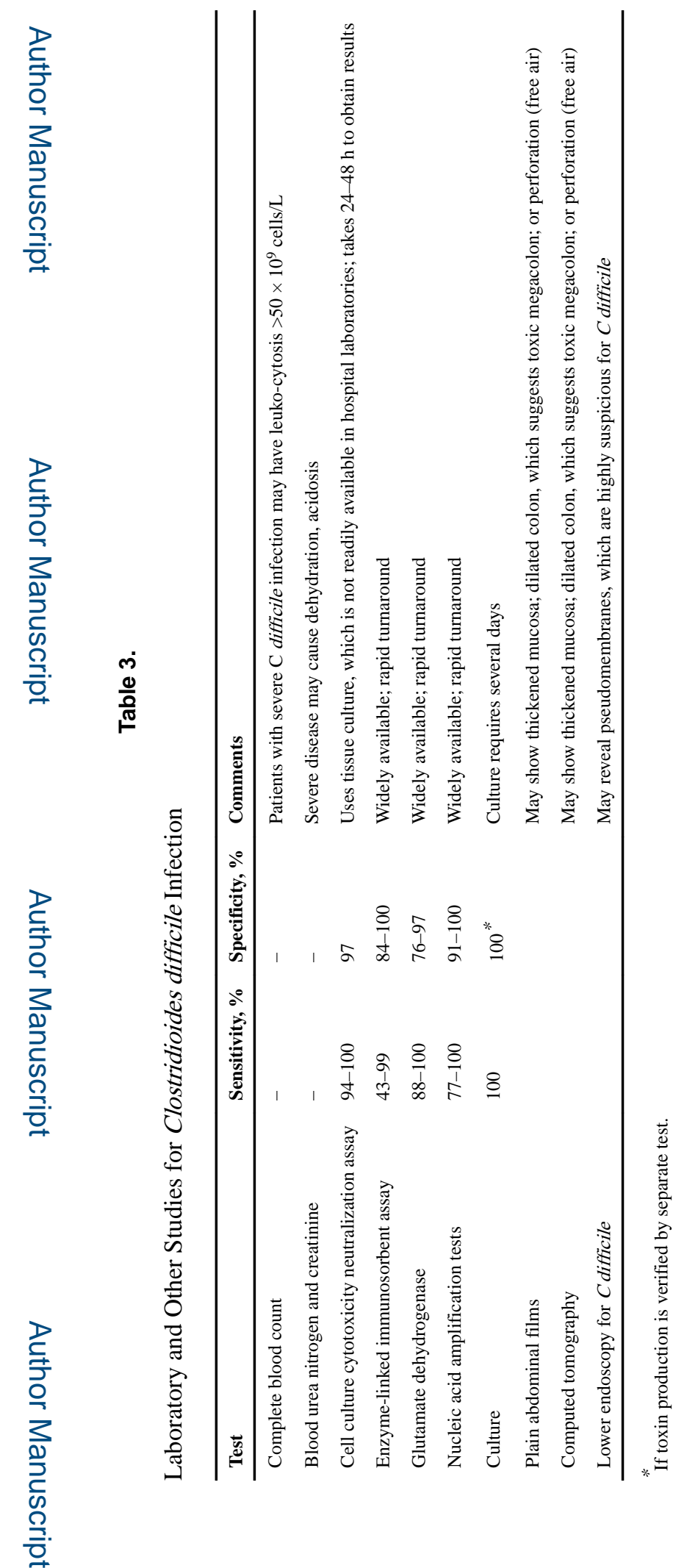

Ann Intern Med. Author manuscript; available in PMC 2019 October 02. 


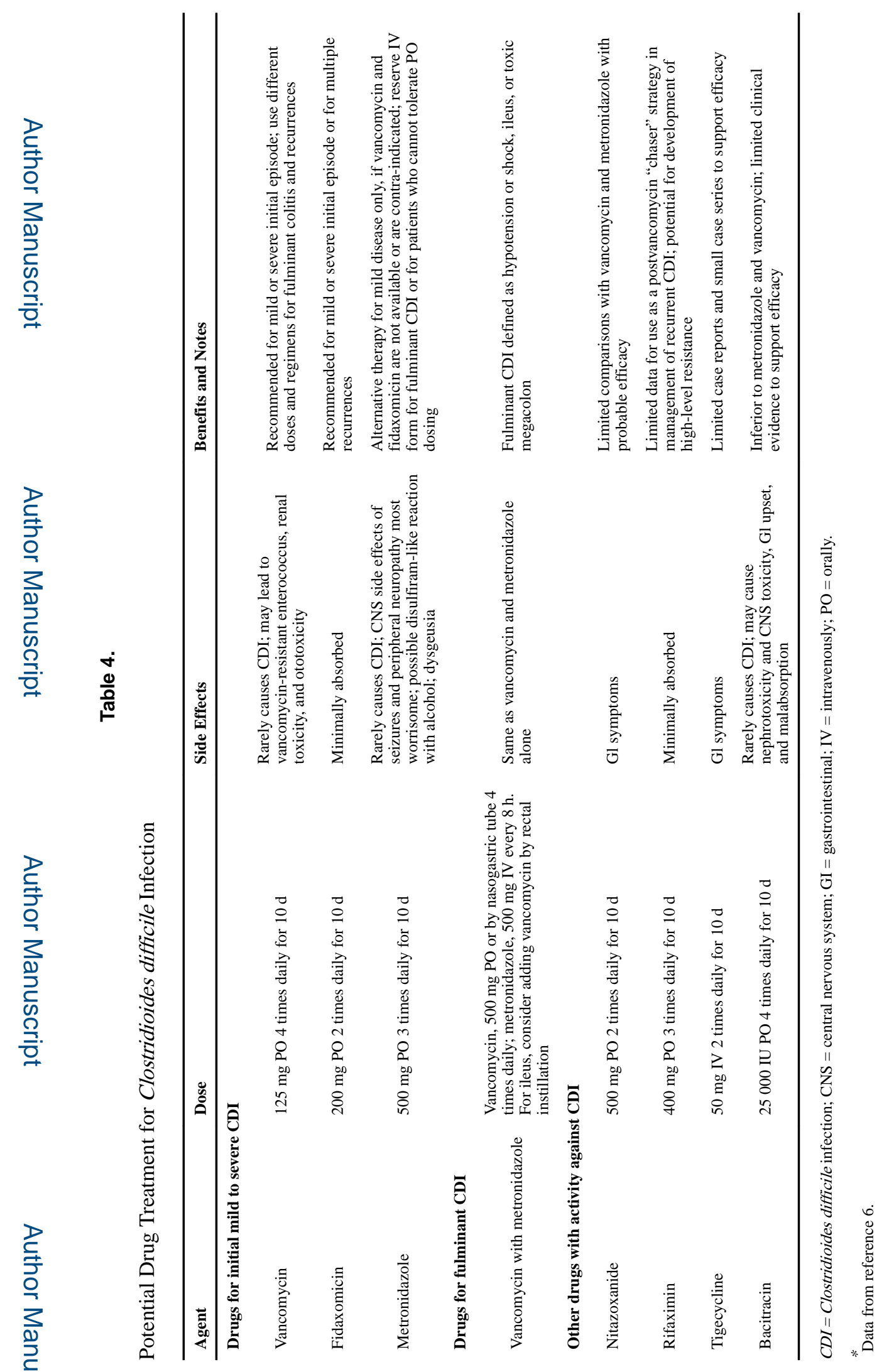

Ann Intern Med. Author manuscript; available in PMC 2019 October 02. 